\title{
Population pharmacokinetics and pharmacogenetics of once daily tacrolimus formulation in stable liver transplant recipients
}

\author{
D. J. A. R Moes ${ }^{1}$ - S. A. S van der Bent ${ }^{2}$ - J. J. Swen ${ }^{1} \cdot$ T. van der Straaten ${ }^{1}$. \\ A. Inderson ${ }^{2}$ - E. Olofsen ${ }^{3}$ - H. W. Verspaget ${ }^{2}$ - H. J. Guchelaar ${ }^{1}$. \\ J. den Hartigh ${ }^{1}$ - B. van Hoek ${ }^{2}$
}

Received: 24 April 2015 / Accepted: 5 October 2015 / Published online: 31 October 2015

(C) The Author(s) 2015. This article is published with open access at Springerlink.com

\begin{abstract}
Purpose The once daily formulation of tacrolimus is an important immunosuppressive drug. Interpatient variability in metabolism has been related to genetic variation in CYP $3 A 4$ and CYP3A5. However, in liver transplantation, both donor and recipient genotypes may affect pharmacokinetics. The primary objective of this study was to investigate the effect of CYP $3 A 4^{*} 22$ and $C Y P 3 A 5^{*} 3$ of both donor and recipient on once daily tacrolimus pharmacokinetics. The secondary objective was to develop a limited sampling model able to accurately predict exposure.

Methods Stable liver transplant patients receiving once daily tacrolimus $(N=66)$ were included. Population pharmacokinetic analysis was performed with patients of whom DNA was available $(N=49)$, and demographic factors, $C Y P 3 A 4 * 22$ and $C Y P 3 A 5^{*} 3$, were tested as covariates. Moreover, a limited sampling model was developed using data of 66 patients.

Results Pharmacokinetics was best described by a twocompartment model with delayed absorption. CYP $3 A 5^{*} 1$
\end{abstract}

Both authors D. J. A. R Moes and S. A. S van der Bent contributed equally to this manuscript.

Electronic supplementary material The online version of this article (doi:10.1007/s00228-015-1963-3) contains supplementary material, which is available to authorized users.

D. J. A. R Moes

d.j.a.r.moes@lumc.nl

1 Department of Clinical Pharmacy and Toxicology, Leiden University Medical Center, Albinusdreef 2, 2333, ZA, Leiden, The Netherlands

2 Department of Gastroenterology and Hepatology, Leiden University Medical Center, Leiden, The Netherlands

3 Department of Anesthesiology, Leiden University Medical Center, Leiden, The Netherlands carrying recipients engrafted with a $C Y P 3 A 5^{*} 1$ carrying liver had an average 1.7-fold higher clearance compared to noncarriers. $C Y P 3 A 5^{*} 1$ carrying recipients engrafted with a $C Y P 3 A 5^{*} 1$ non-carrying liver or vice versa showed an average 1.3-fold higher clearance compared with non-carriers. CYP $3 A 4 * 22$ was not significantly associated with once daily tacrolimus pharmacokinetics. Using 0,2 , and $3 \mathrm{~h}$ postdose as limited sampling model resulted in significantly improved prediction of tacrolimus exposure compared with trough concentration.

Conclusions Both donor and recipient CYP $3 A 5$ genotype significantly influences tacrolimus once daily pharmacokinetics. In contrast, $C Y P 3 A 4^{*} 22$ appears not suitable as biomarker. The developed limited sampling model can be used to accurately estimate tacrolimus once daily exposure.

Keywords Once daily tacrolimus $\cdot$ Advagraf $\cdot$ Population pharmacokinetics $\cdot$ Pharmacogenetics $\cdot$ Liver transplantation

\section{Introduction}

Prolonged release tacrolimus (Advagraf ${ }^{\circledR}$ ) is currently in many centers for the standard formulation of the calcineurin inhibitor tacrolimus in liver transplantation. Advagraf is a once-daily formulation of tacrolimus (ODTac), originally developed to improve adherence which is an important risk factor for rejection and graft loss [1]. Tacrolimus is characterized by a narrow therapeutic window and highly variable pharmacokinetics necessitating therapeutic drug monitoring (TDM) to individualize the dose and prevent rejection or toxicity such as leukopenia and renal toxicity [2]. Tacrolimus is primarily metabolized by the cytochrome P450 enzymes CYP3A4 and CYP3A5 [3]. Differences in activity of metabolizing enzymes are responsible for a large part of the variability in 
pharmacokinetics [3]. Genetic polymorphisms in CYP3A4 and $C Y P 3 A 5$ are known to cause clinically relevant variability in tacrolimus pharmacokinetics in solid organs transplantation [4]. However, since CYP3A4 and CYP3A5 enzymes are both expressed in liver and intestine, in liver transplantation, both genetics of the donor and recipient are of importance. Several studies investigated the role of genetic variants encoding for CYP3A5 in tacrolimus pharmacokinetics in liver transplant recipients [5-11] but were primarily conducted in pediatric and Asian populations. Both donor and recipient CYP3A5 genotype influenced tacrolimus pharmacokinetics in these studies. CYP $3 A 4 * 22$ was only investigated in two different studies in pediatric and Asian liver transplant recipients [6, 12]. Tacrolimus is also a substrate of P-glycoprotein (ABCB1); however, to date, no clinically relevant polymorphisms have been discovered $[13,14]$ and therefore ABCB1 polymorphisms are not included in the scope of the current study. TDM of ODTac is generally performed using trough concentrations $\left(\mathrm{C}_{\text {trough }}\right)$. However, in theory, most informative for true exposure is the area under the blood concentration versus time curve (AUC). This choice has a practical aspect since TDM based on trapezoidal AUC is more laborious for the clinic and inconvenient for the patient since multiple concentration markers are needed for accurate AUC calculation. A limited sampling strategy could help influence the choice of performing TDM based on $\mathrm{C}_{\text {trough }}$ or AUC. Limited sampling models have been developed for twice-daily tacrolimus [15] in liver transplant recipients and for ODTac in renal transplant recipients [16]; however, whether these are also applicable for ODTac in liver transplant recipients is unknown. The primary objective of this study was to develop a population pharmacokinetic model of ODTac in stable liver transplant recipients and to evaluate the effect of $C Y P 3 A 5^{*} 3$ and $C Y P 3 A 4^{*} 22$ of both donor and recipient on tacrolimus pharmacokinetics for initial dose differentiation. The secondary objective was to develop a limited sampling strategy to enable prediction of ODTac exposure in liver transplant recipients in an efficient way and to compare it with widely used $\mathrm{C}_{\text {trough }}$ monitoring.

\section{Methods}

Patients During a prospective study, clinical data were collected from 66 stable liver transplant recipients treated with immunosuppressive therapy based on once-daily tacrolimus (Advagraf $^{\circledR}$, Astellas, Leiden, The Netherlands, further referred to as ODTac) after recent conversion from twice-daily tacrolimus (Prograft ${ }^{\circledR}$ ). The DNA of recipient and donor was available for 49 patients. These 49 patients were included for the development of the population PK model and covariate analysis. The donor DNA was not available from the remaining 17 patients. Inclusion criteria of the subjects were at least 18 years old, stable daily dose of twice-daily tacrolimus for at least 3 months, no infections or other complications, bilirubin and albumin levels within clinical reference range, and stable graft function at the moment of conversion. The study was approved by the Medical Ethics Committee of Leiden University Medical Center and patients gave written informed consent. ODTac therapy was started at the same daily dose as of twice-daily tacrolimus. Routine TDM samples were obtained (at least) 2 weeks after conversion from twice-daily tacrolimus to ODTac.

Bioanalytics TDM during the study was performed on the basis of trapezoidal rule (kinfit MW/Pharm ${ }^{\circledR}$ ), blood concentration at $t=0,1,2,3,4$, and $6 \mathrm{~h}$ using MW/Pharm version 3.5 (Mediware, Groningen, The Netherlands) [17]. Quantification of tacrolimus TDM samples in whole blood with LC-MS/MS was performed with a validated assay capable of analyzing everolimus, sirolimus, cyclosporine, and tacrolimus simultaneously. Details concerning the LC-MS/MS system are provided in Supplementary File 1. The lower limit of quantification for tacrolimus was $0.4 \mu \mathrm{g} / \mathrm{L}$. Assay performance, in terms of limits of quantification, was in agreement with the guidelines regarding bioanalytical method validation of Shah et al. [18]. Supplementary Table 1 shows the samples distribution.

Genotyping assays DNA was isolated from EDTA blood from liver transplant recipients and from donor spleen or liver [19]. CYP $3 A 4^{*} 22$ was determined with TaqMan 7500 (Applied Biosystems, Nieuwerkerk aan de IJssel, The Netherlands) with a custom designed assay, according to the manufacturers' protocol. CYP $3 A 5^{*} 3$ was determined with Pyrosequencer 96MA (Isogen, IJsselstein, The Netherlands). Further details with regard to the genotyping protocol are provided in Supplementary Table 2. All allele frequency distributions were in Hardy-Weinberg equilibrium. To explore the combined effect of both recipient and donor genotypes, the following combinations were made for CYP3A5: $\mathrm{C} 1$, donor and recipient are CYP $3 \mathrm{~A} 5 * 1$ noncarriers; $\mathrm{C} 2$, recipient is $\mathrm{CYP} 3 \mathrm{~A} 5 * 1$ carrier and donor is non-carrier; $\mathrm{C} 3$, recipient is $\mathrm{CYP} 3 \mathrm{~A} 5 * 1$ non-carrier and donor is carrier; and $\mathrm{C} 4$, both donor and recipient are CYP $3 \mathrm{~A} 5 * 1$ carriers. The following combinations were made for CYP $3 A 4$ : $\mathrm{C} 1$, donor and recipient are CYP3A4*22 non-carriers; $\mathrm{C}$, recipient is CYP3A4*22 carrier and donor is non-carrier; $\mathrm{C} 3$, recipient is CYP3A4*22 non-carrier and donor is carrier; and $\mathrm{C} 4$, both donor and recipient are CYP3A4*22 carriers.

Pharmacokinetic modeling Nonlinear mixed effects modeling was used to estimate once-daily tacrolimus (Advagraf) pharmacokinetic parameters from blood concentration-time data. NONMEM (v7.2.1, Icon Development Solutions, Ellicott City, MD) was used for modeling ODTac pharmacokinetics, using PsN toolkit 3.7.6 [20] and Piranã version 2.8.1 [21] as modeling environment. Results were analyzed using 
the statistical software package R (v2.15.2). First-order conditional estimation method with interaction (FOCE-I) was used throughout the analysis. Model selection was based on statistical significance, goodness of fit, and stability. Throughout the model building process, an altered model was chosen over a precursor model if a difference in the objective functions ( -2 $\log$-likelihood) was $>6.63(P<0.01$, with 1 degree of freedom, assuming an $X^{2}$ distribution).

\section{Base model}

Initially, the model was developed exclusively on pharmacokinetic data without covariates. The concentration-time data were reviewed for completeness and consistency of sampling and dosing times. Plots of observed concentration-time data were examined. Subsequently, one- and two-compartmental pharmacokinetic models with first-order elimination were compared to find the best fit of the concentration-time data. The value for bioavailability was fixed to 0.23 which was based on literature [22]. Furthermore, the use of transit compartments and a lag time for drug absorption were explored.

\section{Covariate analysis}

Diagnostic plots were constructed of the random effects of clearance (CL), distribution volume of the central compartment $(\mathrm{Vc})$ and absorption rate constant $\left(K_{\mathrm{a}}\right)$ versus the recipient demographic (age, weight, sex, ethnicity, height, lean body weight (LBW), ideal body weight (IBW), body surface area (BSA), body mass index (BMI), hematocrit, hemoglobin, albumin, creatinine, primary diagnosis and co-medications (also weighted residual vs. co-medications plots), and donor and recipient pharmacogenetic (CYP3A4 and CYP $3 A 5$ polymorphisms) characteristics. Criteria for evaluation of comedication were a minimum frequency of administration and probability of interaction based on literature. Genetic polymorphisms were selected based on theoretical relationship and minimal allele frequency $(>0.10)$ to assure detection of clinically relevant effects on ODTac PK. Based on these plots, further testing in the pharmacostatistical model was performed. Subsequently, selected covariate relationships were evaluated by forward inclusion and backward deletion procedure $(P<0.05$ and $P<0.01$, respectively). A covariate effect was only maintained in the model if the inclusion resulted in a reduction in random variability and improved model fit.

The influence of continuous covariates on pharmacokinetic parameters was tested according to an allometric function. For example, the effect of ideal body weight on apparent clearance $(\mathrm{CL} / \mathrm{F})$ was tested using the following equation:

$\mathrm{CL} / \mathrm{F}=\mathrm{TV}(\mathrm{CL}) \times(\mathrm{IBW} / \text { mediancov })^{\theta_{\mathrm{IBW}}}$

where $\mathrm{TV}(\mathrm{CL})$ is the typical value of clearance for a patient with the median covariate value (mediancov) and $\theta_{\mathrm{IBW}}$ is the estimated influential factor for ideal body weight. The effect of the genetic polymorphisms and other categorical covariates was tested using the equation:

$\mathrm{CL} / \mathrm{F}=\mathrm{TV}(\mathrm{CL}) \times\left(1+\theta_{\text {cov }}\right)$

where TV(CL) represents the clearance of patients with $\theta_{\text {cov }}$ equal to 0 (i.e., $C Y P 3 A 5^{*} 3 / * 3$ carriers or $C Y P 3 A 4 * 1 / * 1$ ) and $\theta_{\text {cov }}$ is the estimated influential factor for the comparator group. For instance, if the estimated value $\theta_{\text {cov }}$ is 0.3 , the clearance of the mutant group is on average $30 \%$ higher than the reference group. Covariates were tested for all the pharmacokinetic parameters for which interpatient variability was estimated.

\section{Visual predictive check with prediction-correction}

A prediction corrected visual predictive check (predcorrVPC) was used to evaluate the performance of candidate and final models of ODTac pharmacokinetics, by simulation of 500 simulated datasets [23]. Bin separators in the VPC were set at the lowest densities of sample points over time, since observations were spread around nominal time points, i.e., this positions the bins such that the periods with densest sampling were in the middle of the bins. Shrinkage in between subject variability (BSV) and residual errors was automatically calculated by NONMEM v7.2.1. to assess the informativeness of the data for using individual predictions in the evaluation of model fit. The distribution (median and 10th and 90th percentiles) of the simulated concentration-time courses was compared with the distribution of the observed values in the original dataset. Differences and overlap of the simulated and original distributions indicated the accuracy of the identified model.

\section{Limited sampling strategy}

\section{Patients and data collection}

For the development of a limited sampling strategy, 66 AUCs from 66 different patients were available, consisting of the 49 patients used in covariate analysis and an additional 17 patients of whom no DNA was available. Demographic parameters of these 66 patients are presented in Table 1. Pharmacokinetic profiles consisted of six blood samples collected over $6 \mathrm{~h}$ (before dose and 1, 2, 3, 4, and $6 \mathrm{~h}$ postdose).

\section{Pharmacokinetic and statistical analysis}

For the development of a limited sampling model (LSM), we calculated the predictive performance of different limited sampling methods (limited sampling models and a limited 
Table 1 Clinical characteristics

\begin{tabular}{|c|c|c|c|c|c|c|}
\hline \multicolumn{4}{|c|}{ Population pharmacokinetics and pharmacogenetics model dataset } & \multicolumn{3}{|c|}{ Limited sampling dataset } \\
\hline Recipient characteristics & Number (proportions) & Mean \pm SD & Median (range) & Number (proportions) & Mean \pm SD & Median (range) \\
\hline Male & $31(63 \%)$ & & & $41(62 \%)$ & & \\
\hline Female & $18(37 \%)$ & & & $25(38 \%)$ & & \\
\hline Age (years) & & $54 \pm 11$ & $55(29-69)$ & & $54 \pm 11$ & $55(29-69)$ \\
\hline Caucasian & $45(92 \%)$ & & & $59(89 \%)$ & & \\
\hline Weight (kg) & & $84 \pm 18$ & $84(50-131)$ & & $83 \pm 17$ & $82(50-131)$ \\
\hline Body Surface Area $\left(\mathrm{m}^{2}\right)$ & & $2 \pm 0.23$ & $2(1.5-2.6)$ & & $2.0 \pm 0.23$ & $2.0(1.5-2.6)$ \\
\hline Lean Body Mass (kg) & & $59 \pm 10$ & $59(40-80)$ & & $59 \pm 9.8$ & $59(40-80)$ \\
\hline Ideal Body Weight (kg) & & $66 \pm 7$ & $68(51-80)$ & & $66 \pm 7.5$ & $68(51-82)$ \\
\hline Height (cm) & & $173 \pm 8$ & $174(155-190)$ & & $173 \pm 9$ & $174(155-193)$ \\
\hline Creatinine $(\mu \mathrm{mol} / \mathrm{L})$ & & $95 \pm 26$ & $97(41-191)$ & & $97 \pm 27$ & $96(41-191)$ \\
\hline Albumin $(\mathrm{g} / \mathrm{L})$ & & $45 \pm 3$ & $45(35-54)$ & & $45 \pm 3$ & $45(35-54)$ \\
\hline Hemoglobin $(\mathrm{mmol} / \mathrm{L})$ & & $8.48 \pm 0.99$ & $8.6(6-10.2)$ & & $8.5 \pm 1.0$ & $8.6(5.7-10.8)$ \\
\hline Hematocrit $(\mathrm{L} / \mathrm{L})$ & & $0.42 \pm 0.04$ & $0.42(0.30-0.50)$ & & $0.42 \pm 0.04$ & $0.42(0.29-0.52)$ \\
\hline \multicolumn{7}{|l|}{ Primary diagnosis } \\
\hline Alcoholic liver disease & $12(24.5 \%)$ & & & $16(24 \%)$ & & \\
\hline Hepatitis B & $1(2 \%)$ & & & $5(8 \%)$ & & \\
\hline Hepatitis C & $4(8 \%)$ & & & $6(9 \%)$ & & \\
\hline Primary sclerosing cholangitis & $9(18 \%)$ & & & $10(15 \%)$ & & \\
\hline Primary biliary cirrhosis & $2(4 \%)$ & & & $2(3 \%)$ & & \\
\hline Nonalcoholic steatohepatitis & $3(6 \%)$ & & & $3(5 \%)$ & & \\
\hline Wilson's disease & $1(2 \%)$ & & & $3(5 \%)$ & & \\
\hline Cystic liver disease & $4(8 \%)$ & & & $5(8 \%)$ & & \\
\hline Hepatocellular carcinoma & $1(2 \%)$ & & & $1(2 \%)$ & & \\
\hline Cryptogenic liver disease & $2(4 \%)$ & & & $2(3 \%)$ & & \\
\hline Auto-immune hepatitis & $1(2 \%)$ & & & $1(2 \%)$ & & \\
\hline Other & $9(18 \%)$ & & & $12(18 \%)$ & & \\
\hline \multicolumn{7}{|l|}{ Exposure } \\
\hline Advagraf dose (mg) & & $3.6 \pm 2.2$ & $3(0.5-14)$ & & $3.5 \pm 2.0$ & $3(1-14)$ \\
\hline Advagraf $\mathrm{AUC}_{24}(\mu \mathrm{g} * \mathrm{~h} / \mathrm{L})$ & & $170 \pm 55$ & $162(72-330)$ & & $164 \pm 53$ & $162(50-330)$ \\
\hline Concentrations $(\mu \mathrm{g} / \mathrm{L})$ & & $8.5 \pm 3.7$ & $8.1(1.8-20.7)$ & & $8.3 \pm 3.7$ & $8(1.3-20.7)$ \\
\hline \multicolumn{7}{|l|}{ Renal function } \\
\hline Creatinine clearance $(\mathrm{mL} / \mathrm{min})^{\mathrm{a}}$ & & $87 \pm 24$ & $87(33-120)$ & & $85 \pm 23$ & $85(33-120)$ \\
\hline
\end{tabular}

${ }^{\text {a }}$ MDRD when $<60 \mathrm{~mL} / \mathrm{min}$, Cockgroft Gault when $>60 \mathrm{ml} / \mathrm{min}$ (cutoff $120 \mathrm{ml} / \mathrm{min}$ ), $\mathrm{AUC}_{24}=$ area under the blood concentration-time curve $(24 \mathrm{~h}$ )

sampling formula). "True" exposure (FULL $\mathrm{AUC}_{24}$ ) was calculated using post hoc estimation in NONMEM with the final model $\left(\mathrm{AUC}_{24}=\left(\left(\mathrm{DOSE}^{*} \mathrm{~F}\right) / \mathrm{CL}\right)\right.$. LSM AUC 24 was calculated by selecting several concentration-time points and combinations of time points and fitting the data points with post hoc estimation in NONMEM with the final model. Subsequently, the FULL $\mathrm{AUC}_{24}$ and $\mathrm{LSM} \mathrm{AUC} 24$ of all individuals were compared. Since $\mathrm{C}_{\text {trough }}$ is widely used in TDM also, a limited sampling formula (LSF) by means of a linear regression equation of $\mathrm{C}_{\text {trough }}$ vs. FULL $\mathrm{AUC}_{24}$ was calculated to show the difference between the limited sampling formula and a limited sampling model. Pearson correlation coefficient test was performed to determine the correlation between FULL $\mathrm{AUC}_{24}$ and limited sampling method $\mathrm{AUC}_{24}$. To evaluate the performance of the limited sampling methods, the 17 additional patients were also evaluated separately and compared with the overall results. The formulas of the used predictive performance measures are presented in Supplementary Table 3.

\section{Results}

\section{Patients, pharmacokinetic, and pharmacogenetic data}

Forty-nine adult liver transplant recipients, 31 men, and 18 women were included for the development of the population PK model and covariate analysis. The majority was Caucasian (92\%). Mean age was $54 \pm 11$ years (range, 29-69 years). Mean bodyweight was $77.5 \pm 11.8 \mathrm{~kg}(50-121 \mathrm{~kg})$. The dataset consisted of 282 samples. Demographic characteristics 
Table 2 Genotype frequencies in studied population $(n=49)$

\begin{tabular}{|c|c|c|c|c|}
\hline Gene & $\mathrm{SNP}(\mathrm{s})$ & $\begin{array}{l}\text { Nucleotide position } \\
\text { and alleles }\end{array}$ & Genotype & $\begin{array}{l}\text { Frequency } \\
{[N(\%)]}\end{array}$ \\
\hline
\end{tabular}

Recipient

CYP3A4

$\begin{array}{llll}\text { rs35599367 } & \mathrm{C}>\mathrm{T} & \mathrm{C} / \mathrm{C} & 36 \\ & & \mathrm{C} / \mathrm{T} & 11 \\ & \mathrm{~T} / \mathrm{T} & 2\end{array}$

CYP3A5

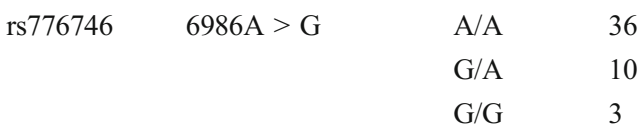

Donor

CYP3A4

$\begin{array}{llll}\text { rs35599367 } & \mathrm{C}>\mathrm{T} & \mathrm{C} / \mathrm{C} & 40 \\ & & \mathrm{C} / \mathrm{T} & 8 \\ & & \mathrm{~T} / \mathrm{T} & 1 \\ & & & \\ \text { rs776746 } & 6986 \mathrm{~A}>\mathrm{G} & \mathrm{A} / \mathrm{A} & 40 \\ & & \mathrm{G} / \mathrm{A} & 9 \\ & & \mathrm{G} / \mathrm{G} & 0\end{array}$

Combination

CYP3A4

$\begin{array}{ll}\text { C1 } & 30 \\ \text { C2 } & 10 \\ \text { C3 } & 6 \\ \text { C4 } & 3\end{array}$

CYP3A5

$\begin{array}{ll}\text { C1 } & 32 \\ \text { C2 } & 8 \\ \text { C3 } & 4 \\ \text { C4 } & 5\end{array}$

CYP3A5: $\mathrm{C} 1$ donor and recipient are CYP3A5*1 non-carriers; C2, recipient is $\mathrm{CYP} 3 \mathrm{~A} 5 * 1$ carrier and donor is non-carrier; $\mathrm{C} 3$, recipient is CYP3A $5 * 1$ non-carrier and donor is carrier; and $\mathrm{C} 4$, both donor and recipient are CYP3A5*1 carriers. For CYP3A4, C1 donor and recipient are CYP3A4*22 non-carriers; $\mathrm{C} 2$, Recipient is CYP3A4*22 carrier and donor is non-carrier; $\mathrm{C} 3$, Recipient is CYP3A4*22 non-carrier and donor is carrier; and $\mathrm{C} 4$ both donor and recipient are CYP3A4*22 carriers. and details about the distribution of dosage and exposure are found in Table 1. Genotype distributions for $C Y P 3 A 5^{*} 3$ and CYP3A4*22 are presented in Table 2.

\section{Structural model development}

The pharmacokinetic data of once-daily tacrolimus was best described by a two-compartmental model with delayed firstorder absorption and first-order elimination from the central compartment. The delayed absorption of once daily tacrolimus was best described with three transit compartments: a first-order rate constant describing the transfer from the dose compartment into the transit compartments and finally into the central compartment (Fig. 1). Random effect parameters for interindividual variability in clearance $(\mathrm{CL})$, volume of central compartment $\left(\mathrm{V}_{\mathrm{c}}\right)$, and rate of absorption $\left(\mathrm{K}_{\mathrm{a}}\right)$ were identified. Thereafter, the random effects were tested for structural relationship with dose and time to create a model with unbiased and randomly distributed random effects for covariate analysis. The shrinkage for random effect parameters on $\mathrm{CL} / \mathrm{F}$ $(0 \%) \mathrm{V}_{\mathrm{c}} / \mathrm{F}(10 \%)$ and $\mathrm{K}_{\mathrm{a}}(15 \%)$ was small which supports unbiased covariate inclusion of the final model. The structural pharmacokinetic model indicated an apparent clearance (CL/ F) of $4.77 \mathrm{~L} / \mathrm{h}$, an apparent central distribution volume of $87.3 \mathrm{~L}\left(\mathrm{~V}_{\mathrm{c}} / \mathrm{F}\right)$ and an apparent peripheral distribution volume of $142 \mathrm{~L}$. The absorption rate constant was $3.65 \mathrm{~h}^{-1}$. Intercompartmental clearance was $14.1 \mathrm{~L} / \mathrm{h}$. The pharmacokinetic data showed interindividual variability in $\mathrm{CL} / \mathrm{F}$ of $45.4 \%$ with a range of $1.17-17.2 \mathrm{~L} / \mathrm{h}$.

\section{Covariate analysis}

\section{Demographics}

The base model was used for the demographic and genetic covariate analysis. Diagnostic plots of random effects of the pharmacokinetic parameters in the initial model against age, weight, sex, hematocrit, hemoglobin, albumin, height, creatinine, IBW, BSA, BMI, LBW, co-medication, primary diagnosis, and ethnicity were built. Plots of weighted residuals versus co-medications were also constructed in case there were changes in concurrent medication regimens. The evaluated
Fig. 1 Schematic representation of the linear two-compartment model with first-order absorption and elimination of once daily tacrolimus (Advagraf) including the transit compartments to describe the absorption phase

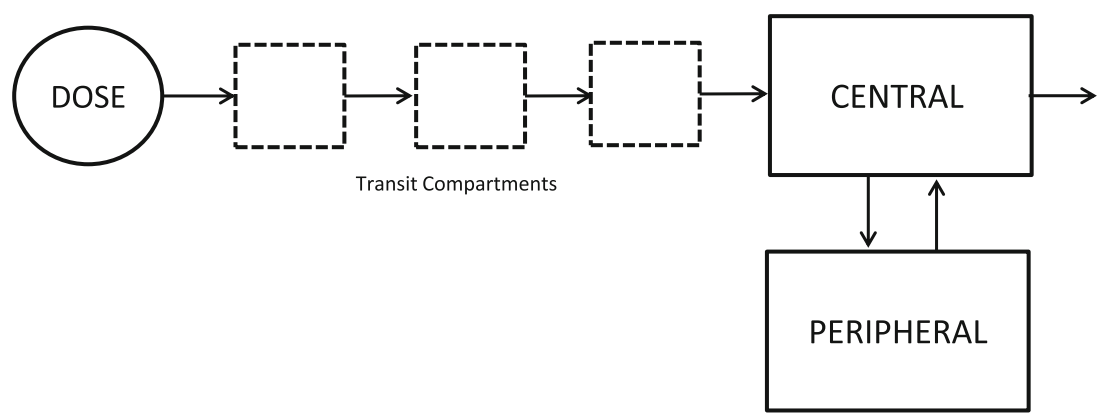


co-medications can be found in Supplementary Table 4. Only IBW and height showed a significant relationship in the univariate covariate analysis $(P<0.05)$, however, in the multivariate analysis $(P<0.01)$, these covariates were not significant. The following were not significant covariates on $\mathrm{CL} / \mathrm{F}$, $\mathrm{V}_{\mathrm{c}} / \mathrm{F}$, or $\mathrm{K}_{\mathrm{a}}$ : age, weight, sex, hematocrit, hemoglobin, albumin, creatinine, BSA, BMI, LBW, co-medication, primary diagnosis, and ethnicity.

\section{Pharmacogenetics}

Diagnostic plots were created of random effects of $\mathrm{CL}, \mathrm{V}_{\mathrm{c}}$, and $\mathrm{K}_{\mathrm{a}}$ against genetic polymorphisms in CYP $3 A 4$ and CYP3A5. The summary of the results of the effect of $C Y P 3 A 4^{*} 22$ and $C Y P 3 A 5^{*} 3$ on tacrolimus clearance is presented in Table 3 and graphically shown in Figs. 2 and 3. CYP $3 A 4^{*} 22$ was not significantly associated with tacrolimus $\mathrm{CL} / \mathrm{F}$. In contrast, $C Y P 3 A 5^{*} 3$ showed a significant effect $(P<0.05)$. Recipients with a genotype with at least one increased activity allele had an average $38 \%$ higher clearance compared to non-carriers. Patients with a donor liver carrying at least one increased activity allele had an average $38 \%$ higher clearance compared to non-carriers. Furthermore, when combining both donor and recipients genotype, C2, $\mathrm{C} 3$, and $\mathrm{C} 4$ showed higher clearance compared to $\mathrm{C} 1$ (33, 33 , and $71 \%$, respectively) $(P<0.01)$. The population pharmacokinetic parameters obtained with the base and final model are presented in Table 4.

The evaluation of the precision of the pharmacokinetic parameters was performed with 1000 bootstrap replicates. The percentage of successful runs was $84 \%$. Moreover, the parameter estimates of the non-successful runs were analyzed and did not deviate from the parameter estimates of the successful runs. The mean values for all fixed effect parameters were within $15 \%$ of those obtained by the final model, indicating good reliability (Table 4). Since different dosages were used during the study, the performance of the model was evaluated with a predictive corrected visual predictive check [15] (Fig. 4). Predictive and observed intervals (10, 90, and median) are almost identical, showing good predictive performance of the final model.

In Fig. 5, the $\mathrm{C}_{\text {trough }}$ and FULL $\mathrm{AUC}_{24}$ correlation is presented with the $\mathrm{C}_{\text {trough }}$ and corresponding FULL $\mathrm{AUC}_{24}$. Although a relatively good correlation is found between $\mathrm{C}_{\text {trough }}$ and $\mathrm{AUC}_{24}$, a relatively large amount of patients remains at risk for under or over exposure. The $\mathrm{C}_{\text {trough }}$ target range $(4-6 \mu \mathrm{g} / \mathrm{L})$ corresponds with a wide $\mathrm{AUC}_{24}$ range and vice versa. For instance, an AUC of around $160 \mu \mathrm{g} * \mathrm{~h} / \mathrm{L}$ ( $\pm 20 \%$ range, $128-192 \mu \mathrm{g}^{*} \mathrm{~h} / \mathrm{L}$ ) corresponds with a $\mathrm{C}_{\text {trough }}$ of 3.8 but also with a $\mathrm{C}_{\text {trough }}$ of $9.5 \mu \mathrm{g} / \mathrm{L}$.

\section{Development of limited sampling model}

The results of the development of a LSM and the LSF of $\mathrm{C}_{\text {trough }}$ are shown in Fig. 6 and Supplementary Table 5. Predictive performance measurements used are the percentage of predicted AUC's within a $15 \%$ range of the "true" AUC, discordance (\%) (meaning a predicted AUC leading to incorrect dose change), different ways of describing bias, and imprecision (MPE, MAPE, and RSME) and correlation. Figure 6 shows results of four LSMs, both regression lines with $95 \%$ $\mathrm{CI}$ as measurements of predictive performance. The limited sampling formula of $\mathrm{C}_{\text {trough }}\left(22.213 * \mathrm{C}_{\text {trough }}+47.983\right)$ for once-daily tacrolimus in predicting systemic exposure had a moderate correlation with full trapezoidal $\mathrm{AUC}_{24}$ (a discordance of $18.2 \%$, a mean absolute percentage prediction error of $13.3 \%$, and $R^{2}=0.72$ ). The best single point marker was $\mathrm{C}_{\text {trough }}$ (discordance, $12.1 \%$; mean absolute percentage
Table 3 CYP3A4 \& CYP3A5 covariate analysis results

\begin{tabular}{llllll}
\hline Covariate tested & DOFV & $P$ value & & Mean value (\%) & $95 \%$ CI \\
\hline $\begin{array}{l}\text { Advagraf base model } \\
+ \text { Recipient } C Y P 3 A 4^{*} 22\end{array}$ & 1.330 & 0.249 & & 17 & -9 to 43 \\
$\quad+$ Donor CYP3A4*22 & 0.391 & 0.532 & & 0 & -29 to 28 \\
+ CYP3A4*22 combination & 2.036 & 0.565 & $\mathrm{C} 1$ & 0 & -16 to 16 \\
& & & $\mathrm{C} 2$ & 12 & -17 to 41 \\
& & $\mathrm{C} 3$ & -16 & -50 to 18 \\
& & & $\mathrm{C} 4$ & 19 & -19 to 56 \\
+ Recipient CYP3A5*3 & 5.551 & 0.018 & & 38 & 6 to 70 \\
+ Donor CYP3A5*3 & 4.54 & 0.033 & & 38 & 5 to 71 \\
+ CYP3A5*3 combination & 9.106 & 0.003 & $\mathrm{C} 1$ & 0 & -15 to 15 \\
& & & $\mathrm{C} 2$ & 33 & -4 to 71 \\
& & & $\mathrm{C} 3$ & 33 & -8 to 74 \\
& & & $\mathrm{C} 4$ & 71 & 31 to 110 \\
\hline
\end{tabular}

$\triangle O F V$ (delta Objective Function Value $)>3.84(P<0.05)$ and $>6.64(P<0.01$, chi-square test $)$, Mean Value $=$ the percentage deviation compared to the reference group. 


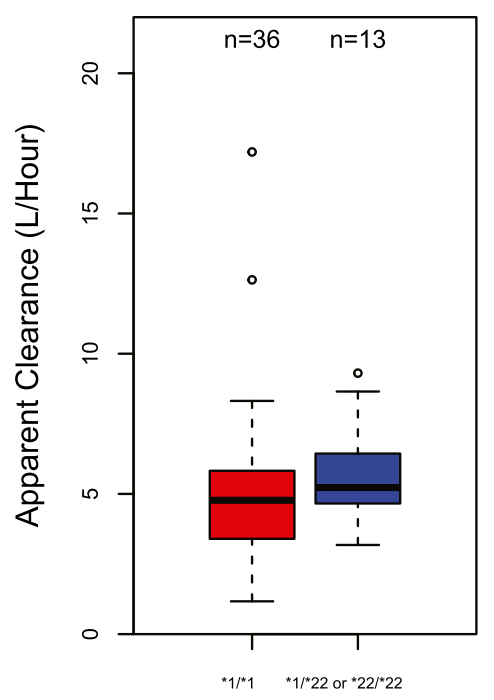

Recipient CYP3A4

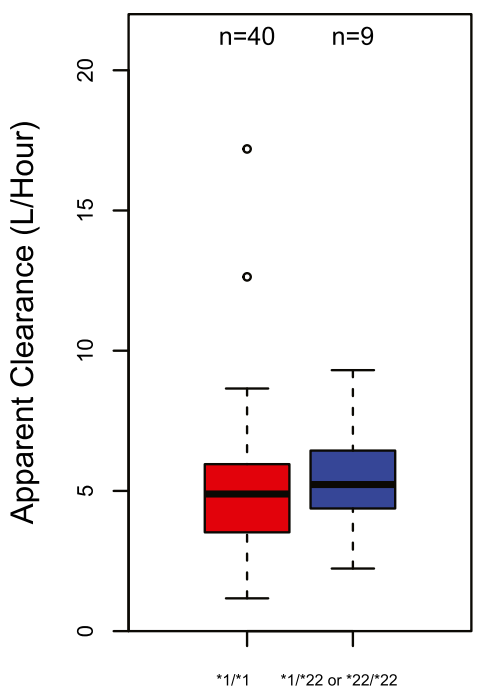

Donor CYP3A4

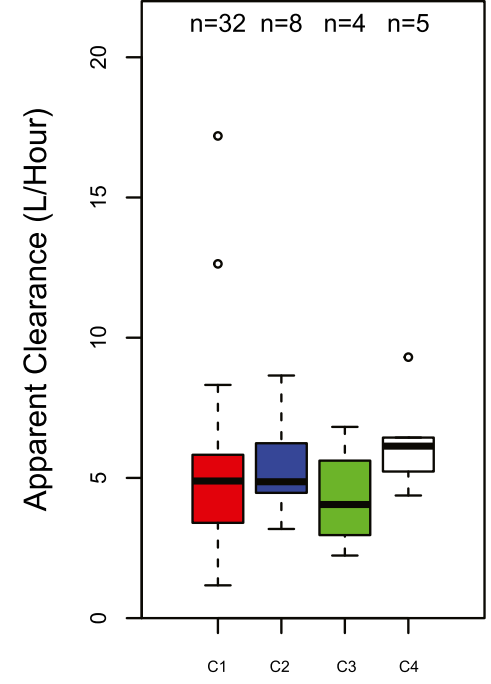

COMBINED CYP3A4
Fig. 2 Boxplots representing the average once-daily tacrolimus apparent clearance $(\mathrm{L} / \mathrm{h})$ of the different genotype groups with error bars and the number of patients in each group. CYP3A $4\left(* 1 /{ }^{*} 1=C Y P 3 A 4 * 22\right.$ noncarriers, $* 1 / * 22$ or $* 22 / * 22=C Y P 3 A 4 * 22$ carriers. CYP3A4

prediction error, $\left.11.42 \% ; R^{2}=0.78\right)$. The best two point markers were $\mathrm{C}_{\text {trough }}$ and $\mathrm{C}_{3}$ (discordance, $3.0 \%$; mean absolute percentage prediction error, $\left.5.2 \% ; R^{2}=0.88\right)$. The best three point markers were $\mathrm{C}_{\text {trough }}, \mathrm{C}_{2}$, and $\mathrm{C}_{3}$ (a discordance of $1.52 \%$ and a mean absolute percentage prediction error of $7.61 \%$, and $R^{2}=0.97$ ). The widely used $\mathrm{C}_{\text {trough }}$ showed less performance with LSF and LSM compared to the two point markers $\mathrm{C}_{\text {trough }}$ and $\mathrm{C}_{3}$. These results were confirmed when evaluating the limited sampling models using only the 17 liver combination: $\mathrm{C} 1$ donor and recipient are $C Y P 3 A 4^{*} 22$ non-carriers; $\mathrm{C}$, recipient is $C Y P 3 A 4^{*} 22$ carrier and donor is non-carrier; $\mathrm{C} 3$, recipient is CYP $3 A 4^{*} 22$ non-carrier and donor is carrier; and $\mathrm{C} 4$, both donor and recipient are $C Y P 3 A 4 * 22$ carriers. *significant

transplant recipients which were not used for the development of the population pharmacokinetic model as showed in Supplementary Table 5 below.

\section{Discussion}

The pharmacokinetics of ODTac in stable liver transplant recipients is best described by a two-compartmental model with

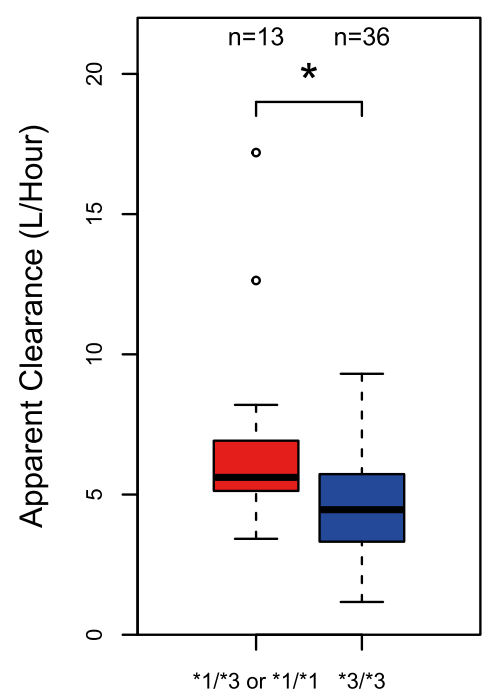

Recipient CYP3A5

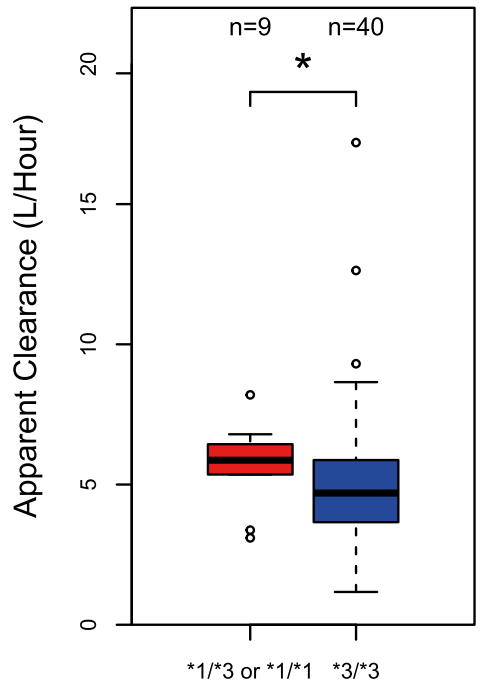

Donor CYP3A5

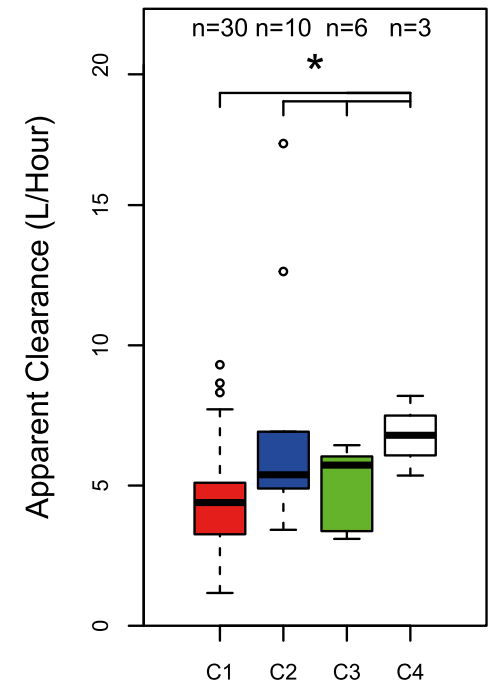

COMBINED CYP3A5
Fig. 3 Boxplots representing the average once-daily tacrolimus apparent clearance $(\mathrm{L} / \mathrm{h})$ of the different genotype groups with error bars and the number of patients in each group. CYP3A $5(* 1 / * 3$ or $* 1 / * 1=C Y P 3 A 5 * 1$ carriers, $* 3 / * 3=C Y P 3 A 5^{*} 1$ non-carriers), CYP3A5 combination: $\mathrm{C} 1$ donor and recipient are $C Y P 3 A 5^{*} 1$ non-carriers; $\mathrm{C} 2$, recipient is CYP $3 A 5^{*} 1$ carrier and donor is non-carrier; $\mathrm{C} 3$, recipient is $C Y P 3 A 5^{*} 1$ non-carrier and donor is carrier; and $\mathrm{C} 4$, both donor and recipient are CYP $3 A 5^{*} 1$ carriers. *Significant 
Table 4 Summary of population pharmacokinetic parameter estimates from the base and final model with relative standard error and shrinkage (\%) and parameter estimates from 1000 bootstrap replicates with $95 \%$ CI

\begin{tabular}{|c|c|c|c|c|c|c|c|c|}
\hline \multirow[b]{2}{*}{ PK parameter } & \multicolumn{3}{|l|}{ Base model } & \multicolumn{3}{|l|}{ Final model } & \multicolumn{2}{|c|}{1000 bootstrap runs } \\
\hline & Mean value & RSE(\%) & Shrinkage (\%) & Mean value & $\operatorname{RSE}(\%)$ & Shrinkage (\%) & Median value & $95 \% \mathrm{CI}$ \\
\hline $\mathrm{CL}(\mathrm{L} / \mathrm{h})$ & 4.77 & 7 & & 4.21 & 8 & & 4.22 & 3.58 to 4.97 \\
\hline F (fixed) & 0.23 & - & & 0.23 & - & & 0.23 & - \\
\hline $\mathrm{V}_{\mathrm{c}}(\mathrm{L})$ & 87.3 & 16 & & 88.3 & 12 & & 82.2 & 56.6 to 110.8 \\
\hline $\mathrm{Q}(\mathrm{L} / \mathrm{h})$ & 14.1 & 20 & & 14 & 22 & & 14.8 & 11.0 to 26.5 \\
\hline $\mathrm{V}_{\mathrm{p}}(\mathrm{L})$ & 142 & 28 & & 145 & 41 & & 131.5 & 86.8 to 348.4 \\
\hline $\mathrm{K}_{\mathrm{a}}(\mathrm{h}-1)$ & 3.65 & 10 & & 3.76 & 10 & & 3.61 & 2.81 to 4.67 \\
\hline \multicolumn{9}{|l|}{ Cyp3A5*3 on CL } \\
\hline $\mathrm{C} 1$ (Reference group)(\%) & & & & 0 & & & 0 & -15 to 15 \\
\hline $\mathrm{C} 2(\%)$ & & & & 33 & & & 32.3 & -2.1 to 81.4 \\
\hline C3 $(\%)$ & & & & 33 & & & 30.5 & -7.0 to 90.0 \\
\hline $\mathrm{C} 4(\%)$ & & & & 71 & & & 67.7 & 35.1 to 121.3 \\
\hline \multicolumn{9}{|l|}{ Interindividual variability } \\
\hline IIV CL (CV\%) & 45.4 & 14 & 0 & 42.8 & 13 & 0 & 41.6 & 31.3 to 53.9 \\
\hline IIV Vc (CV\%) & 86.2 & 14 & 10 & 86.3 & 14 & 9 & 87.3 & 63.6 to 133.1 \\
\hline IIV Ka (CV\%) & 67.4 & 15 & 16 & 65.9 & 14 & 15 & 64.9 & 45.1 to 91.7 \\
\hline \multicolumn{9}{|l|}{ Random residual variability } \\
\hline$\sigma^{1}$ (proportional error $(\%)$ ) & 13 & 9 & 23 & 13 & 8 & 23 & 12.5 & 10.4 to 14.6 \\
\hline
\end{tabular}

first-order absorption and lag time. The delayed absorption was best described with three transit compartments. This study shows for the first time that ODTac pharmacokinetics is not significantly influenced by $C Y P 3 A 4^{*} 22$. In contrast, CYP3A5 genotype of both donor and recipient influences ODTac pharmacokinetics to a clinically relevant extent. Our
Fig. 4 Prediction corrected visual predictive check with $80 \%$ prediction interval. The observed concentrations are shown as closed circles. The lines with round circles represent the observation intervals. The solid lines represent the prediction intervals. The shaded areas around the prediction intervals represent the $95 \%$ confidence interval around each of the prediction interval

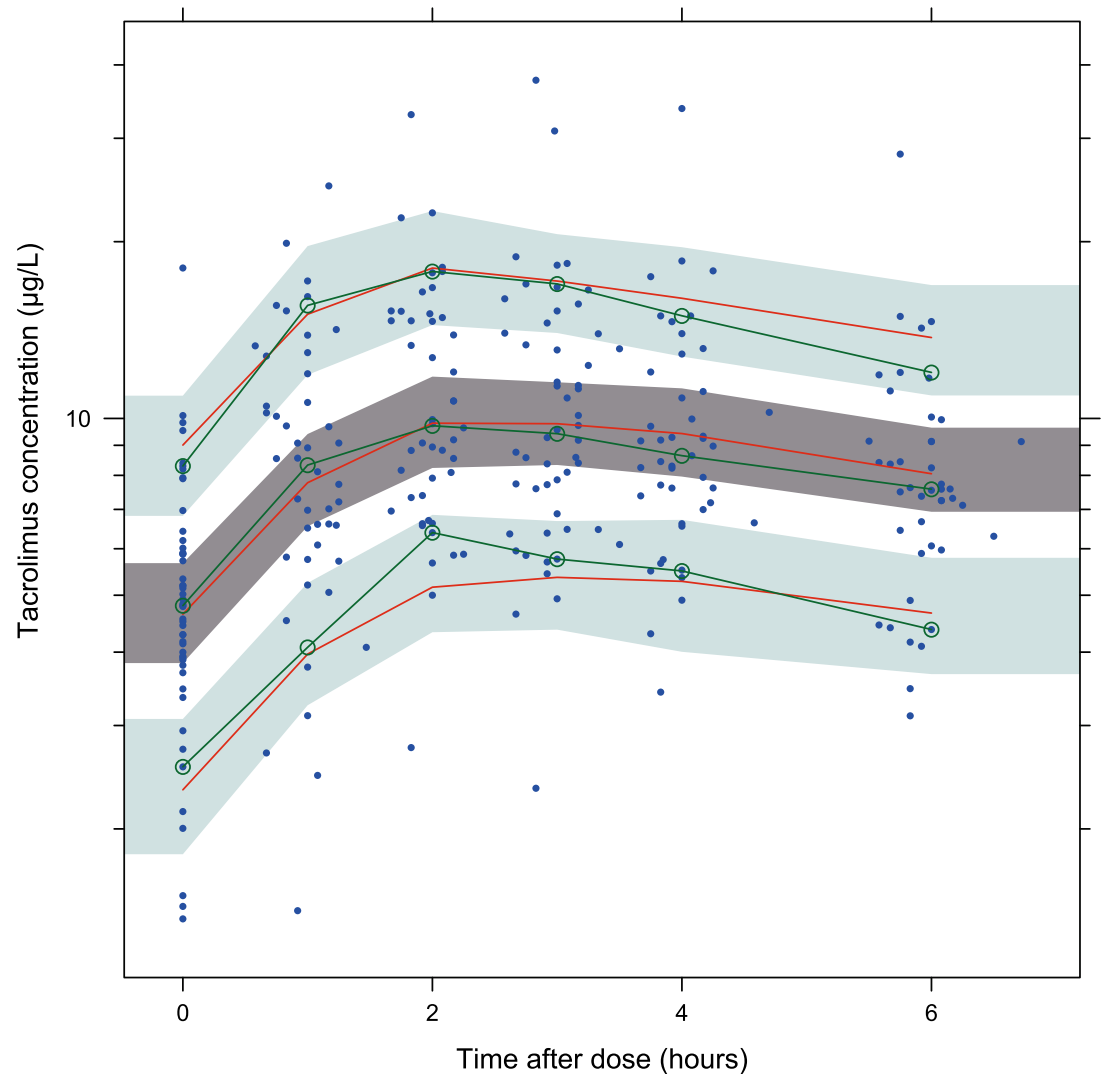


Fig. $5 \mathrm{AUC}_{24}$ correlation of PK profiles of 66 different patients (dose range 1-14 mg). Dotted lines crossing $x$-axis represent $\mathrm{C}_{\text {trough }}$ target area. Dotted lines crossing the $y$-axis represent the $20 \%$ deviation area from the target $\mathrm{AUC}_{24}$ of $160 \mu \mathrm{g} * \mathrm{~h} / \mathrm{L}$ $(128-192 \mu \mathrm{g} * \mathrm{~h} / \mathrm{L}) . \mathrm{AUC}_{24}=$ area under de blood concentrationtime curve from time zero to $24 \mathrm{~h}$

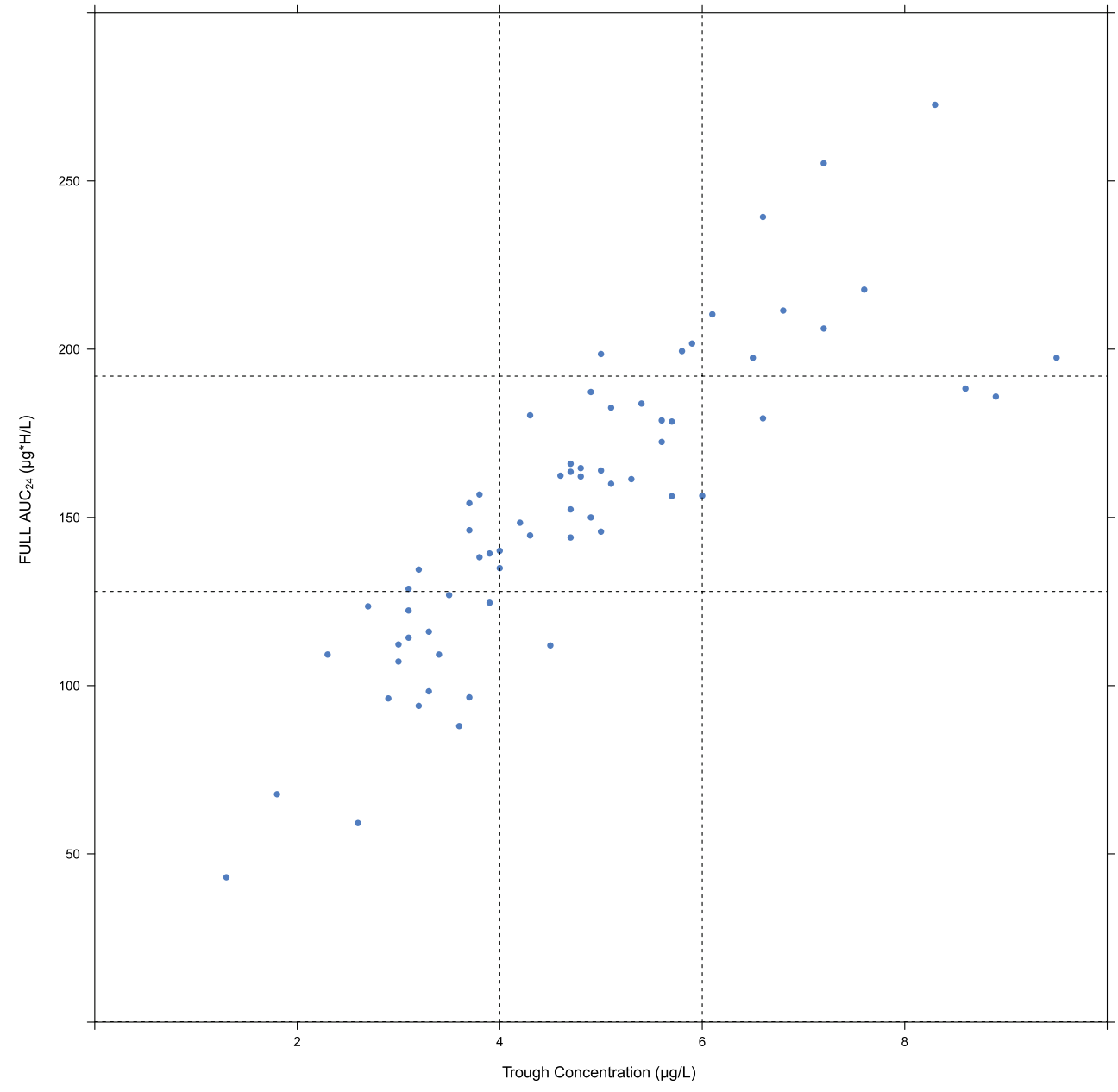

data indicate that both donor and recipient genotype should be considered when establishing an initial ODTac dose of liver transplant recipients. The contribution of the intestine CYP3A5 genotype (recipient) and liver genotype (donor) to tacrolimus pharmacokinetics was comparable. Without considering the genotype, recipients engrafted with a $C Y P 3 A 5^{*} 1$ carrying liver could be at risk of tacrolimus underexposure. This is also technically feasible since tacrolimus is often initiated several days posttransplantation, enabling sufficient time to genotype the donor liver. ODTac pharmacokinetics was not significantly influenced by weight, age, sex, hematocrit, hemoglobin, albumin, height, BMI, BSA, LBW, primary diagnosis, co-medication, and ethnicity. Furthermore, the development of a limited sampling model resulted in identification of a three point concentration marker for accurately predicting ODTac exposure.

In this study, the mean apparent clearance and apparent distribution volume of the central compartment of ODTac were $4.77 \mathrm{~L} / \mathrm{h}$ and $87.3 \mathrm{~L}$, respectively. The PK parameter estimates found in this study are in agreement with those $(\mathrm{CL} / \mathrm{F}=5.72 \mathrm{~L} / \mathrm{H})$ found by Yang et al. [25] and Woilard et al. $(\mathrm{CL} / \mathrm{F}=4.6 \mathrm{~L} / \mathrm{H}$ if $\mathrm{F}=0.23)$ [16] when taking differences in patient population (Asian, pediatric vs. adult Caucasian) and differences in modeling into account.

The relationship between ethnicity and clearance as found in previous studies [26, 27] could not be identified in our study. This is most likely caused by the lack of data on ethnicity of the donor, and the majority (92\%) of the recipients was of Caucasian origin. The fact that we found no effect for concomitant medications is probably caused by the fact that the medications previously found to be of influence on tacrolimus clearance [3] were not administered to our liver transplant recipient population. Prednisolone was administered in too low doses to be of influence $(\leq 10 \mathrm{mg})$. Although established before [28, 29], hematocrit and hemoglobin were not identified as a significant covariate in this analysis, most likely explained by the relative narrow range within the patient population (0.3-0.5 L/L and 6-10.2 mmol/L, respectively).

This is the first comprehensive study investigating the effect of $C Y P 3 A 4^{*} 22$ and $C Y P 3 A 5^{*} 3$ of both donor and recipient on ODTac pharmacokinetics in stable adult Caucasian liver transplant recipients. These polymorphisms were studied before in relation to pharmacokinetics of everolimus, tacrolimus, and cyclosporine in renal transplant recipients [30, 31]. 

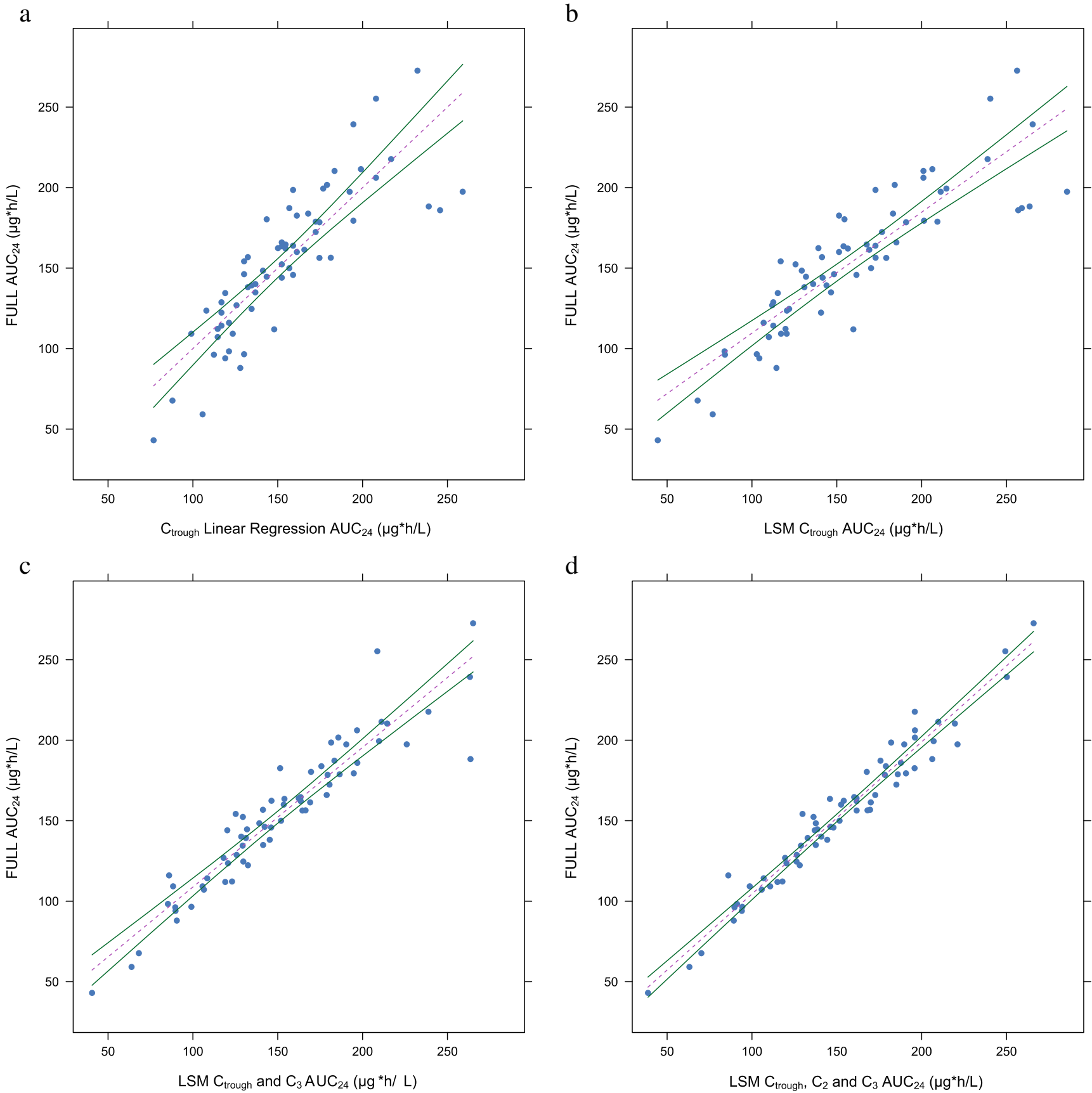

Fig. 6 Regression line (dotted lines) plots of limited sampling methods with $95 \%$ confidence intervals (solid lines). a Predictive performance of $\mathrm{C}_{\text {trough }}$ as limited sampling formula, $\mathbf{b}$ predictive performance of $\mathrm{C}_{\text {trough }}$

For tacrolimus clearance, the relationship to CYP $3 A 5$ genotype has been identified previously $[5,6,30,32]$ and has been adopted in clinical practice in some transplantation centers. However, $C Y P 3 A 4^{*} 22$ has shown less conclusive results $[30,33,34]$. In liver transplant recipients, $C Y P 3 A 4 * 22$ was only investigated in an Asian population where no mutations were identified [12]. The limited effect of $C Y P 3 A 4^{*} 22$ is probably also masked by the more dominant effect of $C Y P 3 A 5^{*} 3$. Allele frequencies found in our dataset were

d

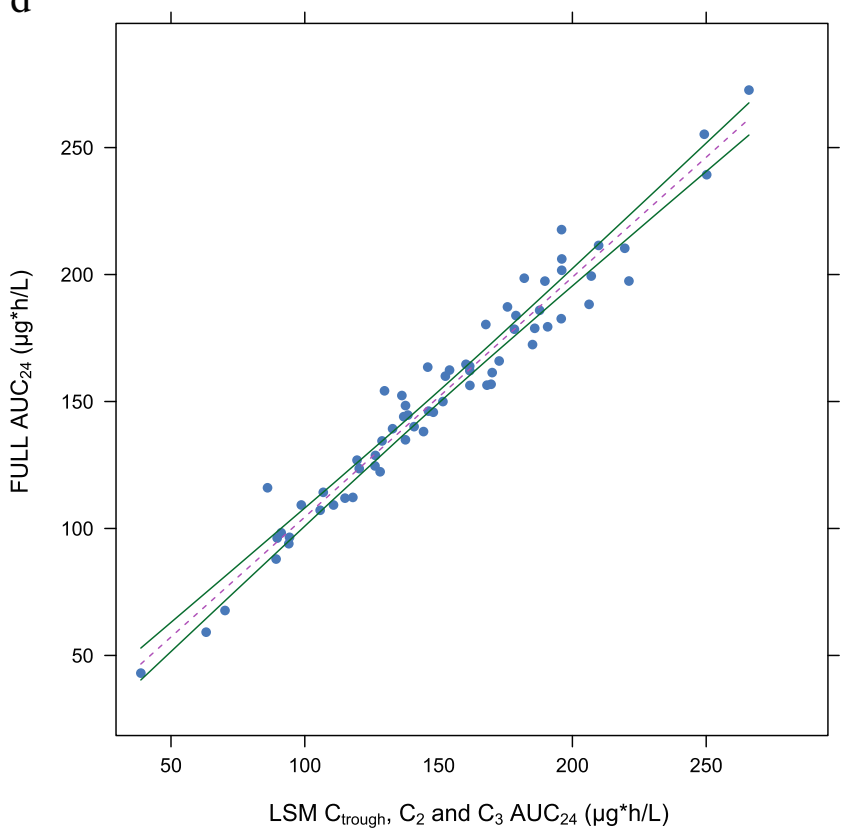

with as sampling model, $\mathbf{c}$ predictive performance of $\mathrm{C}_{\text {trough, } 3}$ as limited sampling model, d predictive performance of $\mathrm{C}_{\text {trough, }, 2,3}$ as limited sampling model

similar to those published previously [35]. The remaining variability of our final model was $42.8 \%$ (a sum of inter- and intraindividual variability) and reflects the wide interindividual variability in CYP3A4/5 expression [36]. Based on our result, we propose to implement genotyping of both donor and recipient to establish an initial dose for ODTac in liver transplant recipients. When aiming for an $\mathrm{AUC}_{24}$ of for instance $320 \mu \mathrm{g} * \mathrm{~h} / \mathrm{L}\left(\mathrm{C}_{\text {trough }} 10-12 \mu \mathrm{g} / \mathrm{L}\right)$, this would mean an initial dose of $6 \mathrm{mg}$ ODTac for non-CYP $3 A 5^{*} 1$ carrying liver 
transplant recipients, $7.5 \mathrm{mg}$ ODTac for $C Y P 3 A 5^{*} 1$ carrying recipients engrafted with a $C Y P 3 A 5^{*} 1$ non-carrying liver or vice versa, and $10 \mathrm{mg}$ ODTac for $C Y P 3 A 5^{*} l$ carrying recipients engrafted with a $C Y P 3 A 5^{*} 1$ carrying liver. Future studies should investigate whether genotype-based dosing also leads to improved clinical endpoints such as lower rejection rates and improved graft survival.

In the present study, a large number of concentration-time data was used for the population pharmacokinetic analysis. However, our study has some limitations: Interoccasion variability could not be established since ODTac AUCmeasurements were only performed on one occasion. Concentrations up to $6 \mathrm{~h}$ were collected and not up to $24 \mathrm{~h}$. Nevertheless, the PK parameters found were in accordance to previously reported ODTac PK studies $[6,16]$ which did not have these disadvantages. Furthermore, data collected from stable liver transplant recipients were used. In general, pharmacokinetics shortly after transplantation is more variable. Using stable liver transplant recipients for this analysis however results in a more unbiased view on the specific genotype contribution on ODTac pharmacokinetics. However, confirmation of the current findings in unstable liver transplant recipients would strengthen our conclusions. Furthermore, a larger study could help to narrow down the $95 \%$ confidence intervals of the genotype effects.

$\mathrm{C}_{\text {trough }}$ monitoring of ODTac is globally widely adopted. Besides the higher impact of assay variability when using one marker to predict ODTac systemic exposure, the correlation between $\mathrm{C}_{\text {trough }}$ and $\mathrm{AUC}_{24}$ is not optimal as shown in the results and could theoretically lead to therapy failure when exposure is $20 \%$ higher or lower as intended [37]. Suboptimal predictive performance of a TDM marker can lead to incorrect dose adjustments resulting in exposure outside the target range. Using trapezoidal, $\mathrm{AUC}_{24}$ has the disadvantage of requiring a relatively high number of blood samples to reach good predictive performance which is a very invasive and inconvenient way of performing TDM. A good alternative is the use of a LSM with good predictive performance.

Since correlation coefficient can be misleading bias, imprecision was calculated to assess the performance of the different LSMs according to the guidelines proposed by Sheiner and Beal [24]. In our study, $\mathrm{C}_{\text {trough }}$ monitoring had a worse performance in estimating $\mathrm{AUC}_{24}$ when using LSF and LSM as compared with $\mathrm{C}_{\text {trough }, 2,3}$ in LSM. Especially, the LSF resulted in a $27 \%$ higher percentage of patients outside of the $15 \%$ radius of the FULL $\mathrm{AUC}_{24}$ and a $16.7 \%$ rise in discordance. $C_{\text {trough }, 2,3}$ and $C_{\text {trough }, 1,3}$ showed comparable performance and are both suitable as limited sampling model. These results were confirmed with limited sampling evaluation of 17 patients which were not used for the development of the final model. In summary, using the three point markers $\mathrm{C}_{\text {trough }}, \mathrm{C}_{2}$, and $\mathrm{C}_{3}$ as limited sampling model is the best option, when taking predictive performance and inconvenience of the sampling for both patient and the clinic into account. The three-point LSM marker $\mathrm{C}_{\text {trough,2,3 }}$ and comparable results of $\mathrm{C}_{\text {trough, } 2,3}$ are in accordance with what previously has been found for ODTac in renal transplant recipients [16].

In conclusion, this study shows that the population pharmacokinetics of ODTac in adult liver transplant recipients is best described by a two-compartment pharmacokinetic model with delayed absorption described by three transit compartments. CYP3A5 genotype but not CYP3A4 genotype of both donor and recipient should be taken into account to establish an initial dose for once-daily tacrolimus. Tacrolimus blood concentrations measured at 0,2 , and $3 \mathrm{~h}$ postdose can be used to accurately estimate ODTac systemic exposure, a clear improvement compared to the widely used $\mathrm{C}_{\text {trough }}$ monitoring.

\section{Compliance with ethical standards}

Conflict of interest The authors declare that they have no competing interests.

Open Access This article is distributed under the terms of the Creative Commons Attribution 4.0 International License (http:// creativecommons.org/licenses/by/4.0/), which permits unrestricted use, distribution, and reproduction in any medium, provided you give appropriate credit to the original author(s) and the source, provide a link to the Creative Commons license, and indicate if changes were made.

\section{References}

1. Ringewald JM, Gidding SS, Crawford SE, et al. (2001) Nonadherence is associated with late rejection in pediatric heart transplant recipients. J Pediatr 139:75-78. doi:10.1067/mpd.2001. 115067

2. Beckebaum S, Cicinnati VR, Radtke A, Kabar I (2013) Calcineurin inhibitors in liver transplantation - still champions or threatened by serious competitors? Liver Int 33:656-665. doi:10.1111/liv.12133

3. Knops N, Levtchenko E, van den Heuvel B, Kuypers D (2013) From gut to kidney: Transporting and metabolizing calcineurininhibitors in solid organ transplantation. Int J Pharm 452:14-35. doi:10.1016/j.ijpharm.2013.05.033

4. De Jonge H, Kuypers DRJ (2008) Pharmacogenetics in solid organ transplantation: current status and future directions. Transplant Rev (Orlando) 22:6-20. doi:10.1016/j.trre.2007.09.002

5. Gómez-Bravo MA, Salcedo M, Fondevila C, et al. (2013) Impact of donor and recipient $\mathrm{CYP} 3 \mathrm{~A} 5$ and $\mathrm{ABCB} 1$ genetic polymorphisms on tacrolimus dosage requirements and rejection in caucasian spanish liver transplant patients. J Clin Pharmacol 53:1146-1154. doi: 10.1002/jcph.154

6. Guy-Viterbo V, Baudet H, Elens L, et al. (2014) Influence of donorrecipient CYP3A4/5 genotypes, age and fluconazole on tacrolimus pharmacokinetics in pediatric liver transplantation: a population approach. Pharmacogenomics 15:1207-1221. doi:10.2217/pgs.14. 75

7. Chen Y, Han L, Xue F, et al. (2014) Personalized tacrolimus dose requirement by CYP3A5 but not $\mathrm{ABCB} 1$ or $\mathrm{ACE}$ genotyping in both recipient and donor after pediatric liver transplantation. PLoS One 9:e109464. doi:10.1371/journal.pone.0109464 
8. Fukudo M, Yano I, Yoshimura A, et al. (2008) Impact of MDR1 and CYP3A5 on the oral clearance of tacrolimus and tacrolimusrelated renal dysfunction in adult living-donor liver transplant patients. Pharmacogenet Genomics 18:413-423. doi:10.1097/FPC. 0b013e3282f9ac01

9. Li D, Zhu JY, Gao J, et al. (2007) Polymorphisms of tumor necrosis factor-alpha, interleukin-10, cytochrome P450 3A5 and ABCB1 in Chinese liver transplant patients treated with immunosuppressant tacrolimus. Clin Chim Acta 383:133-139. doi:10.1016/j.cca.2007. 05.008

10. Uesugi M, Kikuchi M, Shinke H, et al. (2014) Impact of cytochrome P450 3A5 polymorphism in graft livers on the frequency of acute cellular rejection in living-donor liver transplantation. Pharmacogenet Genomics 24:356-366. doi:10.1097/FPC. 0000000000000060

11. Wang WL, Jin J, Shue-Sen Z, et al. (2006) Tacrolimus dose requirement in relation to donor and recipient $\mathrm{ABCB} 1$ and CYP3A5 gene polymorphisms in Chinese liver transplant patients. Liver Transpl 12:775-780. doi:10.1002/lt.20709

12. Shi Y, Li Y, Tang J, et al. (2013) Influence of CYP3A4, CYP3A5 and MDR-1 polymorphisms on tacrolimus pharmacokinetics and early renal dysfunction in liver transplant recipients. Gene 512:226231. doi:10.1016/j.gene.2012.10.048

13. Kurzawski M, Dąbrowska J, Dziewanowski K, et al. (2014) CYP3A5 and CYP3A4, but not ABCB1 polymorphisms affect tacrolimus dose-adjusted trough concentrations in kidney transplant recipients. Pharmacogenomics 15:179-188. doi:10.2217/ pgs.13.199

14. Provenzani A, Santeusanio A, Mathis E, et al. (2013) Pharmacogenetic considerations for optimizing tacrolimus dosing in liver and kidney transplant patients. World J Gastroenterol 19: 9156-9173. doi:10.3748/wjg.v19.i48.9156

15. Langers P, Press RR, den Hartigh J, et al. (2008) Flexible limited sampling model for monitoring tacrolimus in stable patients having undergone liver transplantation with samples 4 to 6 hours after dosing is superior to trough concentration. Ther Drug Monit 30: 456-461. doi:10.1097/FTD.0b013e31818162b9

16. Woillard J-B, de Winter BCM, Kamar N, et al. (2011) Population pharmacokinetic model and Bayesian estimator for two tacrolimus formulations-twice daily Prograf and once daily Advagraf. Br J Clin Pharmacol 71:391-402. doi:10.1111/j.1365-2125.2010. 03837.x

17. Proost JH, Meijer DK (1992) MW/Pharm, an integrated software package for drug dosage regimen calculation and therapeutic drug monitoring. Comput Biol Med 22:155-163

18. Shah VP, Midha KK, Findlay JWA, et al. (2000) Bioanalytical method validation - a revisit with a decade of progress. Pharm Res pp 1551-1557

19. De Rooij BJF, Van Hoek B, Ten Hove WR, et al. (2010) Lectin complement pathway gene profile of donor and recipient determine the risk of bacterial infections after orthotopic liver transplantation. Hepatology 52:1100-1110. doi:10.1002/hep.23782

20. Lindbom L, Pihlgren P, Jonsson EN, Jonsson N (2005) PsNToolkit - a collection of computer intensive statistical methods for non-linear mixed effect modeling using NONMEM. Comput Methods Prog Biomed 79:241-257. doi:10.1016/j.cmpb.2005.04. 005

21. Keizer RJ, van Benten M, Beijnen JH, et al. (2010) Piraña and PCluster: a modeling environment and cluster infrastructure for NONMEM. Comput Methods Prog Biomed 101:72-79. doi:10. 1016/j.cmpb.2010.04.018
22. Scholten EM, Cremers SCLM, Schoemaker RC, et al. (2005) AUCguided dosing of tacrolimus prevents progressive systemic overexposure in renal transplant recipients. Kidney Int 67:2440-2447. doi: 10.1111/j.1523-1755.2005.00352.x

23. N. H. Holford. (2005) The Visual Predictive Check Superiority to Standard Diagnostic (Rorschach) Plots.

24. Sheiner LB, Beal SL (1981) Some suggestions for measuring predictive performance. J Pharmacokinet Biopharm 9:503-512

25. Yang J-W, Liao S-S, Zhu L-Q, et al. (2015) Population pharmacokinetic analysis of tacrolimus early after Chinese pediatric liver transplantation. Int J Clin Pharmacol Ther 53:75-83. doi:10.5414/ CP202189

26. Felipe CR, Silva HT, Machado PGP, et al. (2002) The impact of ethnic miscegenation on tacrolimus clinical pharmacokinetics and therapeutic drug monitoring. Clin Transpl. doi:10.1034/j.13990012.2002.01103.x

27. Staatz CE, Tett SE (2004) Clinical pharmacokinetics and pharmacodynamics of tacrolimus in solid organ transplantation. Clin Pharmacokinet 43:623-653. doi:10.2165/00003088-20044310000001

28. Zahir H, McCaughan C, Gleeson M, et al. (2004) Factors affecting variability in distribution of tacrolimus in liver transplant recipients. Br J Clin Pharmacol 57:298-309. doi:10.1046/j.1365-2125.2003. 02008.x

29. Chen D, Guo F, Shi J, et al. (2013) Association of hemoglobin levels, CYP3A5, and NR1I3 gene polymorphisms with tacrolimus pharmacokinetics in liver transplant patients. Drug Metab Pharmacokinet 1-26

30. Moes DJAR, Swen JJ, den Hartigh J, et al. (2014) Effect of CYP3A4*22, CYP3A5*3, and CYP3A Combined Genotypes on Cyclosporine, Everolimus, and Tacrolimus Pharmacokinetics in Renal Transplantation. CPT pharmacometrics Syst Pharmacol 3: e100. doi:10.1038/psp.2013.78

31. Press RR, Ploeger BA, den Hartigh J, et al. (2009) Explaining variability in tacrolimus pharmacokinetics to optimize early exposure in adult kidney transplant recipients. Ther Drug Monit 31:187197. doi:10.1097/FTD.0b013e31819c3d6d

32. Zhao W, Elie V, Roussey G, et al. (2009) Population pharmacokinetics and pharmacogenetics of tacrolimus in de novo pediatric kidney transplant recipients. Clin Pharmacol Ther 86:609-618. doi:10.1038/clpt.2009.210

33. Elens L, Bouamar R, Hesselink D a, et al. (2011) A new functional CYP3A4 intron 6 polymorphism significantly affects tacrolimus pharmacokinetics in kidney transplant recipients. Clin Chem 57: 1574-1583. doi:10.1373/clinchem.2011.165613

34. Santoro AB, Struchiner CJ, Felipe CR, et al. (2013) CYP3A5 genotype, but not CYP3A4*1b, CYP3A4*22, or hematocrit, predicts tacrolimus dose requirements in Brazilian renal transplant patients. Clin Pharmacol Ther 94:201-202. doi:10.1038/clpt.2013.68

35. Van Schaik RHN, van der Heiden IP, van den Anker JN, Lindemans $\mathrm{J}(2002)\{\mathrm{CYP} 3 \mathrm{~A} 5\}$ variant allele frequencies in Dutch Caucasians. Clin Chem 48:1668-1671

36. Finnström N, Ask B, Dahl M-L, et al. (2002) Intra-individual variation and sex differences in gene expression of cytochromes P450 in circulating leukocytes. Pharm J 2:111-116. doi:10.1038/sj.tpj. 6500086

37. McMaster P, Mirza DF, Ismail T, et al. (1995) Therapeutic drug monitoring of tacrolimus in clinical transplantation. Ther Drug Monit 17:602-605. doi:10.1097/00007691-199512000-00010 